\title{
PT2 Stage Finding
}

National Cancer Institute

\section{Source}

National Cancer Institute. pT2 Stage Finding. NCI Thesaurus. Code C48764.

A pathologic primary tumor TNM stage finding. The definition of PT 2 stage finding depends on the particular type of cancer that it refers to; for example, for breast cancer, PT 2 stage finding is defined as follows: cancer with tumor size more than $2.0 \mathrm{~cm}$, but not more than $5.0 \mathrm{~cm}$ in greatest dimension; for colorectal cancer, pT 2 stage finding is defined as follows: cancer with invasion into the muscularis propria. (from AJCC 6th and 7th Eds.) 